Bond University

Research Repository

\title{
Quantification of accelerometer derived impacts associated with competitive games in National Collegiate Athletic Association division I college football players
}

\author{
Wellman, Aaron D.; Coad, Sam C; Goulet, Grant C.; McLellan, Christopher P \\ Published in: \\ Journal of Strength and Conditioning Research
}

DOI:

10.1519/JSC.0000000000001506

\section{Licence:}

Other

Link to output in Bond University research repository.

Recommended citation(APA):

Wellman, A. D., Coad, S. C., Goulet, G. C., \& McLellan, C. P. (2017). Quantification of accelerometer derived impacts associated with competitive games in National Collegiate Athletic Association division I college football players. Journal of Strength and Conditioning Research, 31(2), 330-338.

https://doi.org/10.1519/JSC.0000000000001506

\section{General rights}

Copyright and moral rights for the publications made accessible in the public portal are retained by the authors and/or other copyright owners and it is a condition of accessing publications that users recognise and abide by the legal requirements associated with these rights.

For more information, or if you believe that this document breaches copyright, please contact the Bond University research repository coordinator 


\title{
QUANTIFICATION OF ACCELEROMETER DERIVED IMPACTS
}

\author{
ASSOCIATED WITH COMPETITIVE GAMES IN NCAA
}

\section{DIVISION I COLLEGE FOOTBALL PLAYERS}

\author{
Aaron D. Wellman¹, Sam C. Coad ${ }^{1}$, Grant C. Goulet ${ }^{2}$, Vernon G. Coffey ${ }^{1}$, Christopher P.
} McLellan ${ }^{1}$

\section{ABSTRACT}

The aims of the present study were to 1) examine positional impact profiles of NCAA division I college football players using global positioning system (GPS) and integrated accelerometry (IA) technology, and 2) determine if positional differences in impact profiles during competition exist within offensive and defensive teams. Thirty-three NCAA Division I Football Bowl Subdivision players were monitored using GPS and IA (GPSports, Canberra, Australia) during 12 regular season games throughout the 2014 season. Individual player datasets $(n=294)$ were divided into offensive and defensive teams, and positional sub-groups. The intensity, number, and distribution of impact forces experienced by players during competition were recorded. Positional differences were found for the distribution of impacts within offensive and defensive teams. Wide receivers (WR) sustained more very light and light to moderate (5-6.5 G force) impacts than other position groups, while the running backs (RB) were involved in more severe 
22 (>10 G force) impacts than all offensive position groups, with the exception of the quarterbacks $(Q B)(p<0.05)$. The defensive back $(D B)$ and linebacker $(L B)$ groups were subject to more very light (5.0-6.0 G force) impacts, and the defensive tackle (DT) group sustained more heavy and very heavy (7.1-10 G force) impacts than other defensive positions $(p<0.05)$. Data from the present study provide novel quantification of positional impact profiles related to the physical demands of college football games and highlight the need for position-specific monitoring and training in the preparation for the impact loads experienced during NCAA Division I football competition.

Key Words: Integrated Accelerometers, monitoring, American football

\section{INTRODUCTION}

American football is a field-based team-sport with competition characterized by repeated short-duration, high-intensity, intermittent movement patterns involving accelerations, decelerations, sprinting, and multi-directional running, followed by periods of low-intensity recovery and tactical strategizing between plays $(10,29)$. In addition to the running demands associated with American football, athletes are exposed to frequent collisions and blunt force trauma associated with repeated contact with opponents and the ground during tackling, blocking, and ball-carrying activities (25). Previous research $(10,24,29)$ has provided some insight into positional movement profiles, including the quantification of high-intensity accelerations and decelerations and sprint distances, along with a rudimentary understanding of exercise to rest ratios 
45 performed during National Collegiate Athletic Association (NCAA) division I football games. However, there is currently limited quantitative information describing the

47 number and intensity of impacts associated with competitive NCAA division I football

48 games. Due to the intense physical demands associated with American football competition, a quantitative examination of position-specific impact profiles may provide an increased understanding of the competitive demands for individuals participating in NCAA division I football games, and novel insight for performance coaches seeking to

52 develop position-specific training and recovery strategies.

Advances in game analysis technologies, such as global positioning system (GPS) and

55 integrated accelerometry (IA), have provided a valid and reliable means of assessing activity profiles $(4,11,12,28)$ and an accurate measure of the impacts associated with

57 collisions in contact team-sports $(3,5,18,21)$. The quantification of competitive movement demands associated with American football (29) and collisions in team-sport competition similar in nature to American football, including rugby league $(1,7,18,19,21,23)$, rugby sevens (9), Australian rules football $(17,27,30)$, and rugby union $(5,20)$ have been reported. Nevertheless, the unique characteristics of American

62 football will dictate specific and distinct physical demands that require detailed examination.

65 The development of GPS technology with IA have allowed the physiological demands of practice and competition in contact team-sport to be quantified by the tracking of player

67 movement demands $(1,7,18,21,29,32)$. Integrated triaxial accelerometers have proven 
68 to be a reliable means of measuring physical activity across multiple players in teamsport (2), and offer a valid tool for detecting the frequency and magnitude of impacts and collisions associated with practice and competition in contact team-sport (6).

71 Impacts may differ in magnitude depending on the intensity of movement undertaken by

72 an athlete and commonly occur in collision sport as a result of decelerations, high-

73 intensity changes in direction, landing from jumps, falling to the ground, and collisions

74 and tackles inherit to collision sport similar to American football (18). While the use of

75 movement profiles collected from GPS and IA offers an assessment of athlete

76 movement during sport-specific activity, the use of impact data collected by GPS and IA

77 during competition and training may provide the most holistic assessment of volume

78 and intensity of exercise in comparison to the traditionally used movement metrics. As

79 such, the quantification of the impact profiles in NCAA division I college football may

80 add novel insight to the physical loading demands placed upon athletes during

81 competition.

82

83 Within American football, each position group has specific physiological and movement

84 demands associated with unique technical and tactical requirements (14). The

85 positional movement profile characteristics associated with NCAA division I football

86 games have been reported (29) and significant $(p<0.05)$ differences between positions

87 groups on offense and defense for high-intensity movement demands have been established. Movement characteristics may provide a rudimentary understanding of the physical demands associated with competition, however, these measures fail to 90 consider the physical demands associated with the contact nature of competitive 
91 football games. American football competition presents a unique model to study

92 position-specific impact profiles that may be similar to other contact team-sports. The characteristics of repeated collisions and the associated blunt force trauma resulting

94 from competition in Rugby League and Rugby Union players have been reported

$95(3,5,18,21)$, and significant $(p<0.05)$ inter-positional differences in total impacts

96 experienced have been demonstrated during competition $(20,26)$. However, uncertainty

97 exists regarding the intensity and frequency of position-specific impact profiles of NCAA division I football players during competition. Despite the widespread inclusion of GPS and IA technology in collegiate American football programs, there remains a paucity of research regarding the characteristics of collisions experienced by players during competition. The accurate determination of impact forces experienced by players during games may provide sports performance specialists with novel insight into the position-specific demands of competition and highlight ways in which GPS and IA data can be used to optimize athlete performance programs.

The aims of the present study were to 1) examine the positional impact profiles of NCAA division I college football players associated with competitive game performance using IA technology, and 2) determine if positional differences in impact profiles exist within offensive and defensive teams. We hypothesized that significant positional differences will exist in the number and intensity of impacts associated with competitive 111 performance in NCAA division I college football. Data obtained will provide information 112 for performance coaches seeking to optimize position-specific training programs. 


\section{METHODS}

\section{EXPERIMENTAL APPROACH TO THE PROBLEM}

To examine the positional impact characteristics during NCAA division I football games,

119 portable accelerometer data were collected from players during 12 regular-season

120 games. All games were 60 minutes in duration, comprised of four 15 minute quarters,

121 each followed by a brief recovery period, and played outdoors between the hours of

$12212: 00$ and 21:00 over a period of thirteen weeks from September to November. All

123 participants were required to participate in a minimum of $75 \%$ of the total offensive or

124 defensive plays for the GPS and IA derived datasets to be included in the present study.

125 Each individual GPS and IA dataset was characterized as constituting either offensive

126 or defensive team performance, and subsequently divided into specific positional

127 groups for the offense that included wide receivers (WR, 41 datasets), quarterbacks

128 (QB, 12 datasets), running backs (RB, 41 datasets), tight ends (TE, 22 datasets),

129 offensive linemen (OL, 37 datasets), and for the defense that included defensive backs

130 (DB, 55 datasets), linebackers (LB, 36 datasets), defensive ends (DE, 33 datasets) and

131 defensive tackles (DT, 17 datasets).

\section{SUBJECTS}


135 Thirty-three National Collegiate Athletic Association (NCAA) Division I Football Bowl 136 Subdivision (FBS) football players (age $20.7 \pm 1.0$ years; height $188.6 \pm 7.2 \mathrm{~cm}$; and

137 mass $106.7 \pm 19.6 \mathrm{~kg}$ ) participated in the present study. Positional anthropometric data

138 are presented in Table 1. All subjects were collegiate athletes whom had been selected 139 to participate in the football program eight months prior to the commencement of the 140 study. All participants in the present study completed the teams' off-season physical 141 development training program that included a full-body strength and power training 142 program and specific skills and conditioning sessions designed to simulate the demands 143 of NCAA division I college football competition. The present study comprises statistical 144 analysis of data collected as part of the day to day student athlete monitoring and 145 testing procedures within the university's football program. Researchers were provided 146 with de-identified GPS and IA datasets from twelve regular season games for analysis.

147 De-identified data included participant playing position for the purposes of position148 specific data analysis. Ethical approval was obtained from the university's human 149 research ethics committee.

155 Global Positioning System Units. The present study used commercially available GPS 156 receivers (SPI HPU, GPSports, Canberra, Australia) which operated in a non-differential 
157 mode at a sampling frequency of $15 \mathrm{~Hz}$. The GPS receivers also contain integrated 158 triaxial accelerometers $(\mathrm{IA})$, which operated at $100 \mathrm{~Hz}$ and assessed the frequency and 159 magnitude of full-body acceleration ( $\mathrm{m} \cdot$ second $\left.^{-2}\right)$ in three dimensions, namely, anterior160 posterior, mediolateral, and vertical $(16,21)$. Impacts were derived from the vector of 161 the $\mathrm{X}-\mathrm{Y}-\mathrm{Z}$ axes of the triaxial accelerometer and calculated as the square root of the 162 sum of the squares of each axis, whereby $27.7 \mathrm{G}$ was the maximum accelerometry 163 output (8). Subjects had previously worn GPS and IA receivers in outdoor training 164 sessions that included football-specific running, and skill-related and game-simulated 165 contact activities during a three-week pre-season training period. Prior to the 166 commencement of each game, GPS receivers were placed outside for 15 minutes to 167 acquire a satellite signal, after which, receivers were placed in a custom designed 168 pocket attached to the shoulder pads of the subjects. Shoulder pads were custom-fit for 169 each individual, thereby minimizing movement of the pads during games. The GPS and 170 IA receivers used in the present study (66 g; $74 \mathrm{~mm} \times 42 \mathrm{~mm} \times 16 \mathrm{~mm}$ ) were positioned

171 in the center of the upper back, slightly superior to the scapulae. Subjects were 172 outfitted with the same GPS receiver for each of the twelve games. Following the 173 completion of games, GPS receivers were removed from the shoulder pads, and 174 subsequently downloaded to a computer for analysis utilizing commercially available 175 software (Team AMS, GPSports, Canberra, Australia). The GPS and IA receivers used 176 in the present study have demonstrated both inter- and intra-accelerometer reliability $177(\mathrm{CV}=1.87-2.21 \%)(13)$, while similar integrated accelerometers have been validated 178 for quantifying the number and intensity of collisions in Rugby League (6) and 
179 measuring peak impacts in team-sport $(\mathrm{CV}=4.8 \%$, filtered at cut-off frequency of $12 \mathrm{~Hz})$ 180 (31).

182 Data provided from IA were assessed as impact profile variables including very light, 183 light to moderate, moderate to heavy, heavy, very heavy, and severe impacts.

184 Classifications of parameters of impact profile variables are described below and 185 presented in Table 2. Each of the GPS and IA derived variables measured in the 186 present study were calculated using commercially available software (Team AMS, 187 GPSports, Canberra, Australia). The impact classification system utilized in the present 188 study was based on methods previously described in Rugby League $(18,21)$, Rugby 189 Union $(3,5,20)$ and manufacturer recommendations (GPSports, Canberra, Australia). 190 GPSports reports peak accelerations, irrespective of the nature of the peaks, from 191 which impact forces can be calculated, given the fact that acceleration is proportional to 192 force if mass is constant (32).

194 Impact Classification System. Player exposure to impact was determined via 195 accelerometer data provided in ' $G$ ' force. A classification system within Team AMS 196 (GPSports, Canberra, Australia) software allows for six zones of impact to be preset 197 and used for subsequent analysis. Zone one is indicative of the lowest intensity of 198 impact, with each zone progressively categorizing impact intensity to zone six, reflecting 199 the highest impact and intensity of movement. Each impact classification was coded as 200 one of six intensities of impact (Table 2). Very light impacts such as accelerations, 
201 decelerations, and changes of direction were considered to be $5.0-6.0 \mathrm{G}$. Light to

202 moderate impacts, such as minor collisions with other players and contact with the

203 ground, were considered to be $6.1-6.5 \mathrm{G}$. Moderate to heavy impacts resulting from

204 physical contact with the opposition at moderate velocities were considered $6.6-7.0 \mathrm{G}$.

205 Heavy impacts from high-intensity collisions were classified as 7.1-8.0 G, while very

206 heavy impacts resulting from high-intensity collisions and high velocities were classified

207 as $8.1-10.0 \mathrm{G}$, and severe impacts resulting from high-intensity collisions between

208 players traveling at high velocities, were classified as those exceeding $10 \mathrm{G}$.

**Insert Table 2 Here ${ }^{\star \star}$

214 All movement variables from the present study were presented as descriptive statistics, 215 mean \pm standard deviation (SD). Hypothesis testing was conducted to determine any 216 main effects for impact profile data between position groups on the offensive and

217 defensive teams. A one-way ANOVA was used to determine positional group main 218 effects. In the event homogeneity of variance assumption was violated, a Welch Robust 219 Test of Equality was used to determine main effects between position groups. For all 220 main effects detected by a one-way ANOVA, post-hoc Bonferroni tests were utilized.

221 Alpha intervals for all hypothesis testing were set at $p<0.05$. To determine the 222 magnitude of main effects and interactions, partial eta-square $\left(n^{2}\right)$ effect size statistics 
223 were adopted, which indicate the percentage of variance accounted for by the effect, 224 with values of $0.01-0.06,0.06-0.15$, and $>0.15$ considered small, moderate, and

225 large, respectively. All statistical analyses were performed using the Statistical Package 226 for the Social Sciences (SPSS for Windows, version 14.0; SPSS, Inc., Chicago, IL. 227 USA).

229 RESULTS

231 Offense: Significant $(p<0.001)$ main effects from ANOVA testing were reported for all 232 impact profile variables measured in the present study for the offensive position groups 233 (Table 3). Post-hoc analysis of impact profile variables, revealed significant $(p<0.05)$ 234 inter-position differences across all impact zones, with the exception of zone 5. The 235 WR position group sustained significantly $(p<0.001)$ more very light (zone 1$)$ impacts 236 than all other offensive position groups, while the OL position group underwent 237 significantly $(p<0.01)$ more very light impacts than RB and QB position groups. Analysis 238 of light to moderate impacts (zone 2$)$ demonstrated a significantly $(\mathrm{p}<0.001)$ greater 239 number of impacts for WR than all other offensive position groups. Similarly, both TE 240 and OL position groups underwent significantly $(p<0.01)$ more light to moderate impacts 241 than RB and QB position groups. The number of moderate to heavy (zone 3) impacts 242 sustained during games were similar among WR, TE, and OL position groups, and 243 significantly $(p<0.001)$ greater than both $Q B$ and RB position groups. The WR and OL 244 position groups experienced significantly $(p<0.001)$ more heavy (zone 4) impacts than 
245 both the RB and QB position groups. Analysis of very heavy (zone 5) impacts revealed 246 no significant $(p<0.05)$ inter-position differences, while the number of severe (zone 6)

247 impacts was significantly $(p<0.05)$ greater for the RB position group than the WR, TE, 248 and OL position groups. Finally, the QB position group sustained significantly more 249 severe (zone 6) impacts than the TE position groups.

251 Defense: Significant $(p<0.001)$ main effects from ANOVA testing were reported for all 252 impact profile zones measured in the present study for the defensive position groups, 253 with the exception of zone 2 impacts (Table 4). Post-hoc analysis of impact profile 254 variables, revealed significant $(p<0.05)$ inter-position differences across all impact 255 zones, with the exception of zone 2 and zone 6 . The DB position group sustained 256 significantly $(p<0.001)$ more very light (zone 1$)$ impacts than the DT and DE position 257 groups, while the LB group was involved in significantly $(p<0.001)$ more very light 258 impacts than the DT position group. The DT position group was involved in significantly 259 ( $p<0.001)$ more moderate to heavy (zone 3), heavy (zone 4), and very heavy (zone 5) 260 impacts than all other defensive position groups, while the DE position group sustained 261 significantly more $(p<0.01)$ heavy and very heavy impacts than the DB position group. 262 The DT position group was involved in more light to moderate (zone 2) impacts than all 263 other defensive position groups, while the DE position group engaged in more severe 264 (zone 6) impacts than any other defensive group, however none of the inter-position 265 differences within either of these impact zones reached a level of significance $(p<0.05)$. 


\section{DISCUSSION}

269 The present study examined the impact profiles associated with competitive games in NCAA division I college football players using portable IA technology, and assessed

271 differences in positional groups within offensive and defensive teams. The results of the

272 present study provide novel insight into the competitive demands experienced by NCAA

273 division I college football players, and may provide scope for the design of position-

274 specific and game-specific physical preparation strategies for coaches seeking to

275 optimize training for the demands of competition. Results from the present study confirm 276 our hypothesis that significant $(p<0.05)$ differences in the number and intensity of

277 impacts associated with competition exist between playing positions in NCAA division I

278 college football players. The most notable findings for competitive game impact profile

279 characteristics of offensive position groups were the WR position group undergoing 280 more zone 1 and 2 (very light and light to moderate) impacts than all other offensive 281 position groups, while the WR and OL group participated in more zone 3 and 4 282 (moderate to heavy and heavy) impacts than the RB group. The RB position group 283 recorded the greatest number of severe impacts throughout the course of competition, 284 which may reflect the characteristic high-velocity collisions with defenders associated 285 with the positional demands of being the primary offensive ball carrier. Defensively, the 286 DB and LB position groups were involved in more zone 1 impacts than all other position 287 groups. The DT group participated in more zone 3, 4, and 5 (moderate to heavy, heavy, 288 and very heavy) impacts than all other defensive position groups, which may be 
289 attributed to the physical demands of the DT position, often involving physical contact with numerous offensive players on each play throughout the course of competition.

292 Comparing the findings of the present study with the existing knowledge of positional 293 game demands is problematic due to the lack of research on impact profiles in 294 American football players. Positional analysis in contact team-sport similar to American 295 football, including Rugby League $(18,21)$ and Rugby Union $(3,5,20,26)$, have 296 demonstrated inter-positional differences in the quantity and intensity of impacts 297 associated with competition, supporting the findings of the present study. Although the 298 influence of the number and intensity of impacts sustained during competition on the 299 duration of post-game recovery in Rugby League players has been investigated $(18,21)$, 300 and the biochemical and endocrine responses to competitive games in American 301 football and Rugby league players have been reported $(15,22)$, there is a lack of 302 research quantifying the relationship between the physical demands of competition and 303 the time-course of recovery associated with college football games. Accordingly, there 304 is a need to establish the relationship between the physical demands of games, 305 including movement and impact profiles, and the subsequent duration of recovery in 306 NCAA division I football players, to provide insight into the effects of competition on 307 athlete recovery.

309 The present study found significant $(p<0.05)$ inter-position differences in the number of impacts encountered during competitive NCAA division I football games. The WR 
311 position group was involved in significantly $(p<0.001)$ more zone 1 impacts than all other

312 offensive position groups. Similarly, on defense, the DB position group recorded

313 significantly $(p<0.001)$ more zone 1 impacts than both the DT and DE position groups,

314 while the LB group recorded significantly $(p<0.001)$ more than the DT position group.

315 The manufacturer (GPSports, Canberra, Australia) of the GPS and IA receivers used in

316 the present study have indicated that low-intensity impacts (2.0-6.0G) are commonly

317 attributed to walking and running, and thus a large amount of very light impacts may be

318 a reflection of running volume throughout the course of competition (8). Additionally,

319 high-intensity changes of direction, falling to the ground, landing from jumps, blocking,

320 collisions, and tackles are all capable of eliciting high-intensity impacts (8). Significant

$321(p<0.05)$ inter-position differences in running volumes in NCAA division I players

322 participating in competitive games have been demonstrated (29). Wellman et. al. (29)

323 examined movement profiles associated with competitive games in NCAA division I

324 football players and reported the WR group covered significantly $(p<0.05)$ more total

325 distance than all other offensive position groups, while the DB and LB position groups

326 covered significantly $(p<0.05)$ more total distance than both DT and DE position groups.

327 The results of Wellman et. al. (29) support the findings of the present study, indicating

328 the increased number of very light impacts detected in the WR and DB position groups

329 may be attributed to the increased running volumes experienced as a result of the

330 unique position-specific demands of these groups. Positional alignment at the

331 commencement of each play that provides greater distance from the placement of the

332 football gives these athletes a larger area for movement, providing increased movement

333 requirements during plays. Additionally, the WR and DB cover more distance between 
334 plays as they are required to jog back to the line of scrimmage at the conclusion of plays, which may be a distance of $20-30 \mathrm{~m}$ to either huddle or re-assume their alignment for subsequent play, while other positions characteristically walk short distances during recovery between plays (24).

Offensively, the WR and OL position groups sustained significantly $(p<0.05)$ more zone 2, 3, and 4 impacts than the RB and QB groups. While no significant inter-position differences were demonstrated with respect to very heavy impacts, the RB position group was involved in significantly $(p<0.05)$ more zone 6 (severe) impacts than all offensive position groups, with the exception of the QB position group. These findings are substantiated by previous descriptions of the nature of severe impacts in contact team-sport (21). McLellan et. al. (21) described severe impacts as being indicative of high-intensity collisions with the opponent, making a direct front-on tackle on an opponent traveling at a high velocity, or being tackled by multiple opponents while running at maximal velocity. The RB position is primarily responsible for carrying the football on running plays and catching the ball on short passing plays, in addition to blocking DT, DE, and LB on passing plays which require protection of the QB. The responsibility of running with the football at high velocities lends itself to direct blunt force trauma, often from multiple opponents, and supports the findings of the present study which indicated an increased number of severe impacts when compared to other offensive positions. Defensively, there were no significant differences between position groups with respect to light to moderate impacts, however the DT group registered significantly $(p<0.05)$ more zone 3,4 , and 5 impacts than all other defensive position 
357 groups. Additionally, the DE position group was involved in significantly $(p<0.05)$ more

358 zone 4 and 5 impacts than the DB group. The greater number of zone 4 and 5 impacts

359 demonstrated within the DT and DE position groups may result from the position-

360 specific demands of these position groups, including rapid accelerations at the

361 commencement of each play, followed by contact with the opposing offensive player,

362 and the subsequent pursuit and tackling of the ball carrier.

364 Inter-positional differences in impact profiles resulting from Rugby Union competition

365 revealed significant $(p<0.05)$ differences between forwards and backs which is

366 consistent with the findings of the present study for offensive and defensive positions

367 (20,26). The significant differences in zone 1-4 impact counts between the WR and OL

368 group when compared to the RB and QB group highlight distinct physiological impact

369 characteristics associated with competition, which may require different training and

370 recovery protocols to achieve optimal performance. The positional differences in the

371 present study may be explained by the position-specific requirements of these

372 individuals. Additionally, the tactics of the offensive team employed during games,

373 namely the number of running and passing plays undertaken, may affect the positional

374 impact distribution. During NCAA division I football games, the WR group is involved in

375 significantly $(p<0.05)$ more maximal acceleration and deceleration efforts than all other

376 offensive position groups (29), likely resulting from the frequent changes of direction

377 due to repeated route running. Additionally, the WR group is responsible for blocking

378 the opposition on running plays and is involved in impacts resulting from physical

379 collisions associated with carrying the ball following a reception on passing plays. The 
OL position group engages in physical contact with the opposition on nearly every play, with the intensity and quantity of impacts presumably dictated largely by offensive strategy. Running plays typically require the OL group to quickly accelerate forward or laterally from a stationary position, initiate contact with the opposition, and move the defender thereby creating a running lane for the ball carrier. Passing plays involve the OL group moving backward or laterally in attempt to protect the $\mathrm{QB}$, while waiting for the opposition to initiate contact. The RB group was involved in significantly $(p<0.05)$ more severe impacts than all other offensive position groups with the exception of the QB group. These findings are likely the result of impacts with opponents, and subsequent impact with the ground, resulting from carrying the ball during running plays. The lack of a significant difference in the number of severe impacts between the RB and QB position groups may be due to offensive strategy. On plays involving the QB as the ball carrier, increased opportunity exists for multiple impacts with the opposition, and similarly, as the number of passing attempts increases, there is greater possibility of the QB being sacked or knocked down.

\section{Defensively, while no significant inter-positional differences were observed for light to} moderate impacts, significant $(p<0.05)$ differences were demonstrated in the number of zone 3,4 , and 5 impacts between the DT group and all other defensive position groups. Characteristically, players in the DT position group accelerate short distances and perform rapid change of direction movements before engaging individual or multiple $\mathrm{OL}$, followed by accelerating to pursue and tackle the ball carrier. The DB group initiates play further from the line of scrimmage and is primarily responsible for defending the 
403 WR on passing plays and provides secondary support on running plays, thereby limiting 404 the amount of physical contact with the opposition. The LB group characteristically 405 commences play 4-5 $\mathrm{m}$ from the line of scrimmage and is generally responsible for 406 providing support on running plays, in addition to defending TE and RB on passing 407 plays. Due to the increased responsibilities in defending running plays within the 408 position-specific responsibilities of the LB group compared to the DB group, and a 409 closer alignment to the line of scrimmage at the initiation of play, the opportunity for 410 physical contact with offensive players is increased. The present study indicated a 411 larger number of zone 4 and 5 impacts for the LB group when compared to the DB 412 group, although these results did not reach significance. Aligning directly on the line of 413 scrimmage prior to the commencement of each play provides opportunity for the DT 414 position group to be involved in physical contact from multiple players on every play, 415 which is indicated in the present study with significantly $(p<0.05)$ more zone 3,4 , and 5 416 impacts recorded for the DT group than all other defensive positions. In similar contact

417 team-sport, significant $(p<0.05)$ correlations have been demonstrated between the 418 number of high-intensity (>7G) impacts sustained and post-match neuromuscular 419 performance decrements and markers of skeletal muscle damage $(18,21)$. As such, the 420 accurate monitoring and prudent modification of practice impact loads of position groups 421 involved in significantly more zone 4-6 impacts during competition may enhance 422 recovery and improve subsequent competitive performance.

424 Significant inter-position differences in the intensity and distribution of impacts 425 associated with NCAA division I college football competition exist. The greater number 
426 of zone 1 and 2 impacts for the WR, DB, and LB groups may be attributed to the

427 significant differences in competitive game running volumes, including accelerations

428 and decelerations, between position groups previously demonstrated (29). The

429 position-specific physicality required of the OL group presumably resulted in more zone

$430 \quad 3$ and 4 impacts, while the significant differences in severe impacts of the RB position

431 group compared to other offensive groups may result from high-intensity collisions from

432 direct tackles at high-velocities, or being tackled by multiple opposing players, as

433 described in investigations of impacts associated with Rugby League competition

$434(18,21)$. The starting position of the DT group upon commencement of each play, along

435 with rapid changes of direction and physical contact with multiple opponents which

436 generally characterizes DT positional demands, resulted in more zone 3,4 , and 5

437 impacts than all other defensive position groups. Collectively, the results of the present

438 study highlight distinct impact profiles for offensive and defensive teams, which may

439 require the development of position-specific training and recovery protocols.

441 The results of the present study provide novel insight into the impact profiles of NCAA

442 division I college football games and provide physical performance staff with quantified

443 information. The present study demonstrated substantial differences in positional impact

444 profiles associated with NCAA division I football games, emphasizing the importance of 445 position-specific training to appropriately prepare players for the rigors of competition. 
The present study provided a novel analysis of the number and intensity of impacts associated with NCAA division I college football games. The findings of this study suggest that repeated high-intensity impacts during NCAA division I football games are

452 position specific in nature and support the use of position-specific training in the 453 preparation of NCAA division I college football players for competitive games. Data

454 from the present study augment our understanding of the competitive demands

455 experienced by NCAA division I college football players, and provide scope for position456 specific training strategies for performance coaches seeking to optimize competitive 457 performance.

Maximizing performance and mitigating the effects of fatigue present unique challenges to performance coaches, and consequently, quantifying the physical demands associated with weekly practice and competition is critical. In contact team-sport similar to American football, the number of impacts exceeding $7 \mathrm{G}$ has been significantly

463 correlated with decreases in neuromuscular performance following competition (18).

464 During the in-season period judicious monitoring, and the subsequent alterations of 465 weekly practice and conditioning loads of individuals within position groups involved in 466 large numbers of impacts, particularly those registering as heavy, very heavy, and 467 severe, may reduce fatigue, expedite recovery, and improve competitive performance. 468 As such, the DT, OL, and WR position groups may benefit from position-specific, and 469 perhaps, individually prescribed practice loads. Because the OL and DT position 470 groups often compete against one another in practice, limiting the number of live 
471 contact drills and scrimmage situations may result in a reduction of intense impacts

472 sustained during the course of a practice week, possibly enhancing recovery and

473 improving subsequent performance. Limiting the amount of contact the WR position

474 sustains in practice sessions is common in American football, and this rationale is

475 substantiated by the present study. Given the significant quantity of severe impacts

476 sustained by the RB position, performance coaches should monitor, and in some cases,

477 reduce the impact load of individual practice sessions by limiting the number of

478 scrimmage situations the RB group is involved in. Data obtained from the study

479 contribute new insight into the competitive demands of NCAA division I college football

480 and provide a foundation from which to implement a systematic approach to the

481 development of individual and position-specific training prescriptions. During the pre-

482 season practice period, monitoring and periodizing training loads based upon position-

483 specific impact profiles may allow performance specialists to scale the intensity of

484 practices to better prepare athletes for forces encountered during competition.

486 ACKNOWLEDGEMENTS

488 No grant aid or manufacturer's aid was received in conjunction with the present study, 489 and no conflicts of interest are declared. The results of this study do not constitute 490 endorsement of the product by the authors or the National Strength and Conditioning 491 Association. 
493

494

495

496

497

498

499

500

501

502

503

504

505

506

507

508

509

510

511

512

513

\section{REFERENCES}

1. Austin, DJ, and Kelly, SJ. Professional Rugby League positional match-play analysis through the use of global positioning system. J Strength Cond Res 28: 187-193, 2013.

2. Boyd, LJ, Ball, K, and Aughey, RJ. The reliability of minimaxx accelerometers for measuring physical activity in Australian football. Int J Sports Physiol Perform 6: 311-321, 2011.

3. Coughlan, GF, Green, BS, Pook, PT, Toolan, E, and O'Connor, SP. Physical game demands in elite rugby union: a global positioning system analysis and possible implications for rehabilitation. J Orthop Sports Phys Ther 8: 600-605, 2011.

4. Coutts, AJ, and Duffield, R. Validity and reliability of GPS devices for measuring movement demands of team sports. J Sci Med Sport 13: 133-135, 2010.

5. Cunniffe, B, Proctor, W, Baker, JS, and Davies, B. An evaluation of the physiological demands of elite rugby union using global positioning system tracking software. J Strength Cond Res 23: 1195-1203, 2009.

6. Gabbett, TJ, Jenkins, DG, and Abernethy, B. Physical collisions and injury during professional rugby league skills training. J Sci Med Sport 13: 578-583, 2010.

7. Gabbett, TJ, Jenkins, DG, and Abernethy, B. Physical demands of professional rugby league training and competition using microtechnology. J Sci Med Sport 15: 80-86, 2011.

8. GPSports, Canberra, Australia. Position on impacts and collisions. November, 2012. 
514 9. Granatelli, G, Gabbett, TJ, Briotti, G, Padulo, J, Buglione, A, D'Ottavio, S, and 515 Ruscello, BM. Match analysis and temporal patterns of fatigue in rugby sevens. J $516 \quad$ Strength Cond Res 28: 728-734, 2014.

517 10. Iosia, MF, and Bishop, PA. Analysis of exercise-to-rest ratios during division ia $518 \quad$ televised football competition. J Strength Cond Res 22: 332-340, 2008.

519 11. Johnston, RD, Watsford, ML, Kelly, SJ, Pine, MJ, and Spurrs, RW. Validity and 520

14. Kraemer, WJ and Gotschalk, LA. Physiology of American football. In: Exercise and Sport Science. W.E. Garrett and D.T. Kirkendall, eds. Philadelphia: Lippincott, Williams and Wilkins, 2000. pp. 795-813.

15. Kraemer, WJ, Spiering, BA, Volek, JS, Martin, GJ, Howard, RL, Ratamess, NA, Hatfield DL, Vingren, JL, Ho, JY, Fragala, MS, Thomas, GA, French, DN, Anderson, JM, Häkkinen, K, and Maresh, CM. Recovery from a national collegiate athletic association division I football game: muscle damage and hormonal status. $J$ Strength Cond Res 23: 2-10, 2009. 
16. Krasnoff, JB, Kohn, MA, Choy, FKK, Doyle, J, Johansen, K, and Painter, PL. Interunit and intraunit reliability of the RT3 triaxial accelerometer. J Phys Act Health 5: 527-538, 2008.

17. Loader, J, Montgomery, P, Williams, MD, Lorenzen, C, and Kemp, JG. Classifying training drills based on movement demands in Australian football. Int $\mathrm{J}$ of Sports Sci Coach 7: 57-67, 2012.

18. McLellan, CP and Lovell, DI. Neuromuscular responses to impact and collision during elite rugby League match play. J Strength Cond Res 26: 1431-1440, 2012.

19. McLellan, CP and Lovell, DI. Performance analysis of professional, semiprofessional, and junior elite rugby league match-play using global positioning systems. J Strength Cond Res 27: 3266-3274, 2013.

20. McLellan, CP, Coad, S, Marsh, D, and Lieschke, M. Performance analysis of super15 rugby match-play using portable micro-technology. J Athl Enhanc 2:5, 2013.

21. McLellan, CP, Lovell, DI, and Gass, GC. Biochemical and endocrine responses to impact and collision during elite rugby league match play. J Strength Cond Res 25: 1553-1562, 2011.

22. McLellan, CP, Lovell, DI, and Gass, GC. Creatine kinase and endocrine responses of elite players pre, during, and post rugby league match play. $J$ Strength Cond Res 24: 2908-2919, 2010.

23. McLellan, CP, Lovell, DI, and Gass, GC. Performance analysis of elite rugby league match play using global positioning systems. J Strength Cond Res 25: 1703-1710, 2011. 
558 24. Rhea, MR, Hunter, RL, and Hunter, TJ. Competition modeling of American football:

559 observational data and implications for high school, collegiate, and professional

560 player conditioning. J Strength Cond Res 20: 58-61, 2006.

561 25. Sterczala, AJ, Flanagan, SD, Looney, DP, Hooper, DR, Szivak, TK, Comstock, BA,

562 White, MT, Dupont. WH, Martin, GJ, Volek, JS, Maresh, CM, and Kraemer, WK.

563 Similar hormonal stress tissue damage in response to national collegiate athletic

564 association (NCAA) division I football games played in consecutive seasons. $J$

$565 \quad$ Strength Cond Res 28: 3234-3238, 2014.

566 26. Suárez-Arrones, LJ, Portillo, LJ, González-Ravé, JM, Muñoz, VE, and Sanchez, F.

567 Match running performance in Spanish elite male rugby union using global

568 positioning system. Isokinet Exerc Sci 20: 77-83, 2012.

569 27. Sullivan, C, Bilsborough, JC, Cianciosi, M, Hocking, J, Cordy, J, and Coutts, AJ.

570 Match score affects activity profile and skill performance in professional Australian

571 football Players. J Sci Med Sport 17: 326-331, 2014.

572 28. Varley, MC, Fairweather, $\mathrm{IH}$, and Aughey, RJ. Validity and reliability of GPS for

573 measuring instantaneous velocity during acceleration, deceleration, and constant

$574 \quad$ motion. J Sports Sci 30: 121-127, 2012.

575 29. Wellman, AW, Coad, SC, Goulet, GC, and McLellan, CP. Quantification of

576 competitive game demands of NCAA division I college football players using global

577 positioning systems. J Strength Cond Res 30:11-19, 2016.

578 30. Wisbey, B, Montgomery, PG, Pyne, DB, and Rattray, B. Quantifying movement

579 demands of AFL football using GPS tracking. J Sci Med Sport 13: 531-536, 2010. 
580 31. Wundersitz, DW, Gastin, PB, Robertson, S, Davey, PC, and Netto, KJ. Validation of 581 a trunk-mounted accelerometer to measure peak impacts during team sport 582 movements. Int J Sports Med 36: 742-746, 2015.

583 32. Young, WB, Hepner, J, and Robbins, DW. Movement demands in Australian rules 584 football as indicators of muscle damage. J Strength Cond Res 26: 492-496, 2012. 